\title{
Activity of the lipoxygenase inhibitor I-phenyl- 3-pyrazolidinone (phenidone) and derivatives on the inhibition of adhesion molecule expression on human umbilical vascular endothelial cells
}

\section{Torsten Hans Schroeder Wolfgang Artur Krueger Hans-Jürgen Dieterich Boris Nohé}

Department of Anaesthesiology and Critical Care Medicine, Tuebingen University Hospital, Tuebingen, Germany
Correspondence:Torsten H Schroeder Department of Anaesthesiology and Critical Care Medicine, University of Tuebingen, Hoppe-Seyler Str. 3, 72076 Tuebingen, Germany

Tel +49 707I 2986622

Fax +49 707I 295533

Email torsten.schroeder@uni-tuebingen.de

\begin{abstract}
Leukocyte adhesion contributes to perfusion abnormalities and tissue damage during trauma, shock or overwhelming inflammation. This study was performed to determine whether the lipoxygenase inhibitor phenidone and derivatives decrease the expression of adhesion molecules on tumor necrosis factor- $\alpha($ TNF- $\alpha)$ stimulated endothelial cells and attenuate leukocyte-endothelial interactions under flow in vitro. TNF- $\alpha$ stimulated human umbilical venous endothelial cells (HUVECs) were incubated with phenidone, 4-methyl-phenidone, 4-4-dimethyl-phenidone, 5-methyl-phenidone, 5-phenyl-phenidone, and 5-methyl-1,(2,5-dichloro-phenyl)-3-pyrazolidone. We tested the inhibition of adhesion molecule expression at different inhibitor concentrations before, during, and after the stimulation of HUVECs. The inhibition of endothelial cell expression on HUVECs was measured by flow cytometry. Rolling and firm adhesion of leukocytes to pretreated endothelium was examined in a parallel plate flow chamber. Phenidone inhibited the expression of intercellular adhesion molecule-1, vascular cell adhesion molecule-1, and endothelial-leukocyte adhesion molecule-1 on HUVECs when added prior to HUVEC stimulation. The inhibitory effect of phenidone was still observed when added simultaneously, but not when added after HUVEC stimulation. 4-4-dimethyl-phenidone and 5-phenyl-phenidone inhibited the expression of adhesion molecules more effectively than phenidone. The attenuation of leukocyte rolling under flow conditions was also significantly more effective with 4-4-dimethyl-phenidone than with phenidone. Lipoxygenase inhibitors might be of therapeutically interest for the treatment of overwhelming systemic inflammation during shock, trauma, and sepsis.
\end{abstract}

Keywords: lipoxygenase inhibitor, adhesion molecules, vascular endothelial cells, TNF- $\alpha$, SIRS

\section{Introduction}

The infiltration of infected tissue by leukocytes is important for the innate immune response. Before leaving the vascular system, the leukocytes must make contact with the endothelial cells of the vessel wall. Once this contact has been established, the leukocytes transmigrate through the tissue and fight local inflammatory processes by various defense mechanisms.

Systemic inflammatory response syndrome (SIRS) is a systemic event and is defined by clinical parameters such as body temperature, heart rate, respiratory insufficiency, and leukocyte count in the context of a typical clinical setting with or without a confirmed infection (Bone 1992). Leukocyte adhesion is a hallmark of shock, overwhelming inflammation and ischemia/reperfusion injury (Vedder et al 1988; Eppihimer and Granger 1997; Singbartl et al 2000). In the case of systemic inflammation, there is 
widespread transmigration of leukocytes from the vascular system through the activated tissue. The high mortality rate associated with this syndrome is due in part to the fact that the inflammatory process is not kept at a local level, but spreads throughout the body. Leukocyte diapedesis has detrimental effects on innate immunity and causes the failure of organs such as kidneys, liver, lungs, etc.

On endothelial cells, the expression of endothelialleukocyte adhesion molecule-1 (E-selectin), ICAM-1 (intercellular adhesion molecule-1), and VCAM-1 (vascular cell adhesion molecule-1) leads to a multistep process of leukocyte-endothelial interaction. Following transient rolling interactions mediated by selectins, the binding of ICAM-1 and VCAM-1 to their integrin counterreceptors results in firm adhesion of the leukocytes, which finally transmigrate into the subendothelial tissue (Jaeschke and Smith 1997; Ramos et al 1997). Concomitant signaling via adhesion molecules activates the interacting cells (Hlasta et al 1991). Since leukocyte-endothelial interactions are a crucial contributor to many aspects of organ dysfunction in critical illness (Singbartl et al 2000), the reduction of adhesion molecule expression on activated endothelial cells could be a therapeutic option to attenuate leukocyte-mediated tissue injury.

5-lipoxygenase pathways are widely distributed within mammalian cells and catalyze the production of leukotrienes, which act as potent biological mediators (Cuzzocrea et al 2004; Zhao et al 2004). Leukotrienes can be synthetized by vascular endothelial cells, smooth muscle cells, neutrophils, macrophages, platelets, etc., and themselves can trigger the expression of adhesion molecules on the surface of endothelial cells and leukocytes (Reilly et al 2004). The principal substrate for leukotrienes is arachidonic acid. In a next step, the enzymes cyclooxygenase and lipoxygenase catalyze the production of prostaglandins and leukotrienes, respectively. The lipoxygenases are classified according to the position at which they oxidize arachidonic acid. Leukotriene B4 (LTB4) is a potent activator of human leukocytes and can induce inflammatory reactions such as polymorphonuclear activation, migration and adhesion by nuclear factor-kappa $\mathrm{B}(\mathrm{NF}-\kappa \mathrm{B})$ activation. The biological potency of leukotrienes has stimulated the search for 5-lipoxygenase inhibitors with antiinflammatory potency in a multitude of medical fields (De Caterina and Zampolli 2004; Gaddi et al 2004; Wang et al 2004).

1-phenyl-3-pyrazolidinone (phenidone) is a combined 5-lipoxygenase and cyclooxygenase inhibitor. Increased lipophilicity of phenidone derivatives is correlated with increased inhibitor potency. By preventing the oxidation of arachidonic acid to 5-HPETE we may be able to inhibit 5-lipoxygenase.

In this study, we tested the ability of phenidone and potent derivatives to inhibit the expression of adhesion molecules E-selectin, ICAM-1, and VCAM-1 on activated human vascular endothelial cells (HUVECs). We also measured their potential to inhibit leukocyte rolling and firm adhesion in a dynamic flow assay.

\section{Materials and methods Antibodies and reagents}

Fluorochrome-conjugated murine monoclonal antibodies (mAb) against $\mathrm{CD} 11 \mathrm{~b}\left(\mathrm{IgG}_{1}\right.$, fluorescein conjugates, Caltag, San Francisco, CA), CD15 (IgM, phycoerythrin-conjugate), CD45, CD62L ( IgG $_{1}$, fluorescein-conjugates, Becton Dickinson, San Jose, CA), Lewis X, E-selectin, VCAM-1 (CD15, CD62E and CD106; IgM and $\mathrm{IgG}_{1}$, fluoresceinconjugates, Southern Biotechnologies, Birmingham, AL),

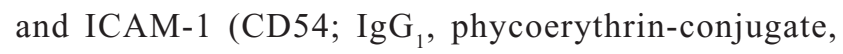
Immunotech, Marseille, France) were used in saturating amounts for subsequent flow cytometric analysis of cell surface antigen expression (FACSort ${ }^{\mathrm{TM}}$, Becton Dickinson, San Jose, CA). Isotype-matched control antibodies were purchased from the manufacturers of the corresponding specific antibodies.

Phenidone and derivatives were obtained from Hampford Research Inc., Stratford, Connecticut, USA (Figure 1). Derivatives were dissolved with DMSO to a final concentration of $0.2 \%$ in cell culture medium. In control experiments, no influence of DMSO on the adhesion molecule expression of activated HUVECs was observed.

\section{Cell culture and human polymorphonuclear neutrophil isolation}

Human umbilical venous endothelial cells (HUVECs) were harvested from freshly prepared umbilical cords by enzymatic treatment of the umbilical vein with collagenase $\mathrm{A}$ $0.1 \%$ (Wakatsuki et al 1999). The cells were grown at $37^{\circ} \mathrm{C}$ and $5 \% \mathrm{CO}_{2}$ in endothelial cell growth medium containing fetal calf serum $2 \%$, epidermal growth factor $0.1 \mathrm{ng} / \mathrm{ml}$, basic fibroblast growth factor $1.0 \mathrm{ng} / \mathrm{ml}$, gentamicin $50 \mu \mathrm{g} / \mathrm{ml}$, amphotericin B $0.05 \mu \mathrm{g} / \mathrm{ml}$ and $20 \mu$ l endothelial cell growth supplement/heparin. This preparation yielded a purity and viability of $>90 \%$ as confirmed by staining for von Willebrand factor and trypan blue exclusion. After the first passage, the cells were plated at high density on either collagen-treated 12-well plates or rectangular coverslips (No. 1.5 thickness, Kindler, Freiburg, Germany) precoated with 


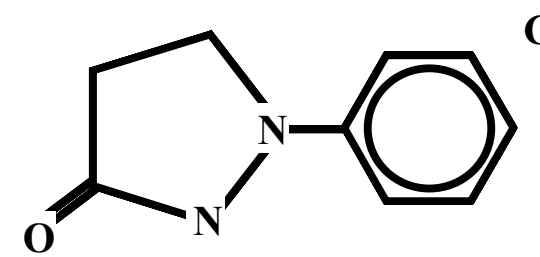

Phenidone

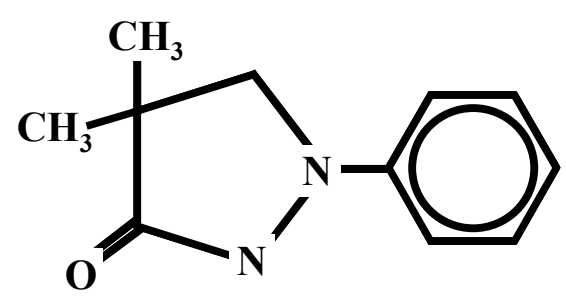

4-4-Di-Methyl-

Phenidone

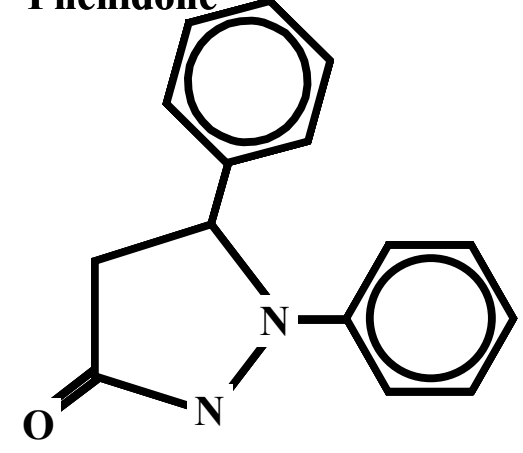

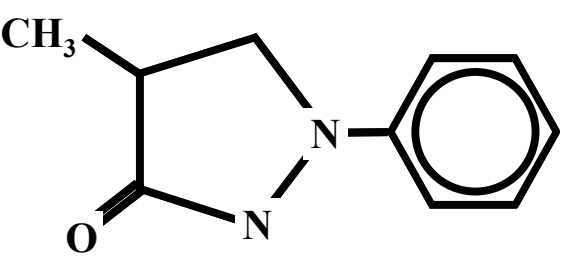

4-Methyl-Phenidone

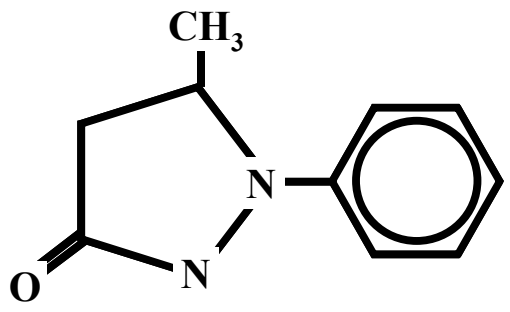

5-Methyl-Phenidone

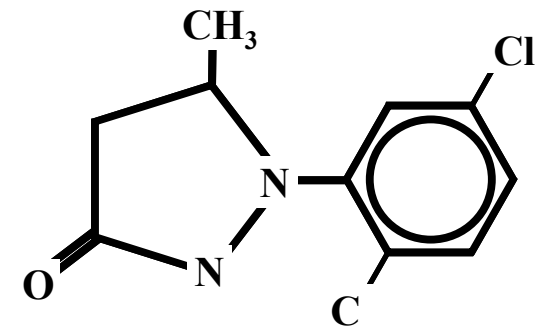

\section{5-Phenyl-Phenidone \\ 5-Methyl-1,(2,5-Di-Chloro-Phenyl)-3- Pyrazolidone}

Figure I Phenidone derivatives.

collagen I and used for the experiment $48 \mathrm{~h}$ later after they had reached confluency.

Human polymorphonuclear neutrophils (PMN) were isolated from citrated blood by density gradient centrifugation at $1700 \mathrm{rpm}$ on a discontinuous Percoll gradient with $63 \%$ and $72 \%$ Percoll in phosphate buffer solution (PBS) (Percoll, $1.130 \mathrm{~g} / \mathrm{ml}$; Amersham Pharmacia Biotech, Uppsala, Sweden). The bottom layer, containing the polymorphonuclear neutrophil granulocytes (PMN), was collected; contaminating erythrocytes were removed by hypotonic lysis in $10 \% \mathrm{NH}_{4} \mathrm{Cl}$ on ice. Following a final wash with cold PBS, the PMN pellet was resuspended in cold medium 199 at $5 \times 10^{7} / \mathrm{ml}$. As determined by light scatter and cell surface antigen analysis of CD15, CD45, CD62L, and CD11b, separation yielded functionally intact, non-activated PMNs at $>90 \%$ purity, with only minimal alterations in surface molecules that are sensitive markers for activation. Samples were obtained after obtaining written consent and approval of the local ethics committee.

\section{Endothelial cell activation}

To determine the inhibitory effect of lipoxygenase-cyclooxygenase inhibitors on adhesion molecule expression on endothelial cells, HUVECs were stimulated with tumor necrosis factor- $\alpha$ (TNF- $\alpha)(0.5 \mathrm{ng} / \mathrm{mL})$ (Sigma, St. Louis, MO, USA) $2 \mathrm{~h}$ before (preincubation), simultaneously with (coincubation), or $2 \mathrm{~h}$ after (postincubation) the addition of the lipoxygenase-cyclooxygenase inhibitor (Figure 2). The inhibitor was added in increasing concentrations up to $2 \mathrm{mMol}$ for $4 \mathrm{~h}$ (pre- and postincubation) or $6 \mathrm{~h}$ (coincubation). The final concentrations of lipoxygenase-cyclooxygenase inhibitors employed in flow assays were determined in preliminary 


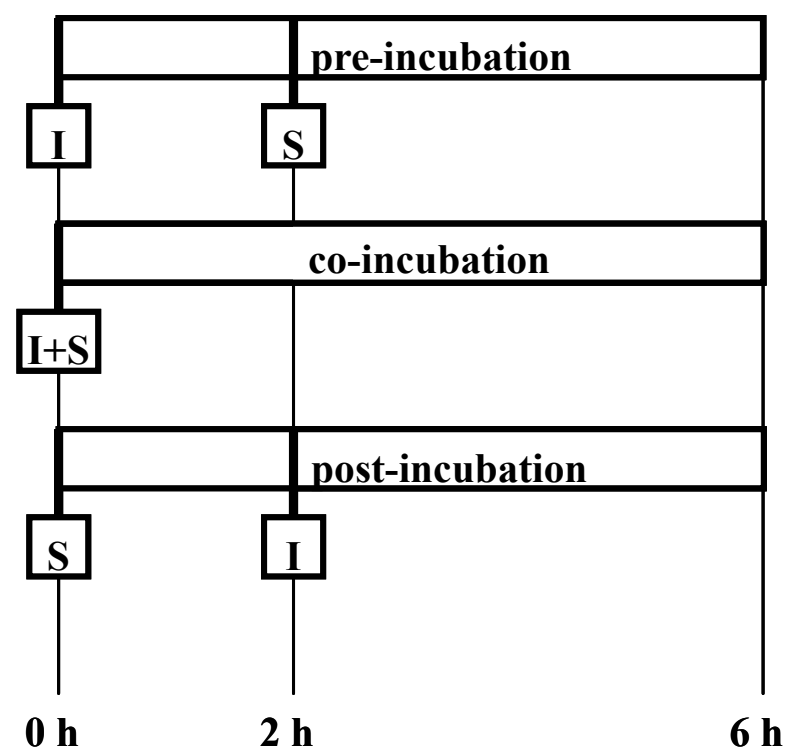

Figure 2 Experimental setup.

Phenidone or derivatives (Inhibitors-I) were added either 2 hours before (preincubation), at the same time as (co-incubation), or 2 hours after the addition of TNF- $\alpha$ (Stimulation-S) to human vascular endothelial cells.

experiments examining the effects of different concentrations of inhibitors on adhesion molecule expression and cell viability. Control experiments consisted of the incubation of HUVECs with medium alone, or the activation of adhesion molecule expression without the addition of an inhibitor. At the end of a $6 \mathrm{~h}$ incubation period, the response to stimulation was determined by flow cytometric analysis of endothelial cell adhesion molecules. Prior to the measurement, HUVECs were labelled with $20 \mu \mathrm{l}$ of mAb against E-selectin, ICAM-1, and VCAM-1 for $30 \mathrm{~min}$ at room temperature, washed, and trypsinized.

\section{Endothelial-PMN interactions in the flow chamber}

Cell adhesion was examined morphometrically from digitized video recordings of perfusion experiments using computer-based image recognition. Corresponding to the above experiments, HUVEC monolayers were grown on coverslips and treated according to the pre-incubation setup described above. After washing, the coverslips were placed within a heatable metal case located on the stage of an inverted microscope (DMIRB, Leica, Bensheim, Germany). The flow rate $Q$ in $\mathrm{ml} / \mathrm{sec}$ necessary to produce the desired shear stress $\tau_{w}$ could be calculated according to the formula $Q=\left(h^{2} w \tau_{w}\right) / 6 \mu$, in which $h$ is the chamber height, $w$ is the width and $\mu$ is the viscosity of the perfusate $(0.007$ poise for isolated neutrophils). We performed the experiments at a shear stress of 2 dynes $/ \mathrm{cm}^{2}$. PMN suspension $\left(10^{6}\right.$ cells $\left./ \mathrm{mL}\right)$ was perfused through the flow chamber via a syringe pump. Total PMN adhesion, including rolling and firm interactions with the endothelial monolayer, was determined from five randomly chosen fields of view $(200 \times$ magnification $)$ at the end of each 10 min perfusion period. PMN were considered to be adherent (sticking) when a cell was moving less than one cell diameter within $10 \mathrm{sec}$ (Figure 5). The number of rolling interactions between PMN and the endothelial cell monolayer were calculated from 60 video sequences derived from a single field of view over a period of 3-4 min during each experimental run. Rolling velocities $(\mu \mathrm{m} / \mathrm{s})$ were calculated as previously described (Nohé et al 2002, 2003). PMN with rolling velocities of $0.7 \mu \mathrm{m} / \mathrm{s}$ were counted as rollers. Data are expressed as percent sticking or rolling cells compared with controls.

\section{Statistical analysis}

Cell surface antigen expression was measured on the basis of mean fluorescence intensities calculated from 5000 single events detected by the flow cytometer for each sample. The effects of the lipooxygenase inhibitors in the flow cytometer analysis are expressed as percent expression of TNF$\alpha$ activation alone minus the unstimulated expression of adhesion molecules on HUVECs. All data were tested for normal distribution and transformed where necessary. Effects of treatment (pre-, co-, post-inhibition) and effects of the derivative concentration on adhesion molecule expression were examined using an analysis of variance (ANOVA) followed by Bonferroni-Holm adjustment. As indicated by an R-square of 0.82 , the ANOVA attributed $82 \%$ of the variation to the model. The inhibitor concentration that lead to a $50 \%$ inhibition of adhesion molecule expression (IC50) was calculated, assuming a logarithmic dose-response relationship. Unless otherwise stated, data are presented as means \pm standard deviation. Statistical significance was set at $\mathrm{p} \leq 0.05$. Statistical computation was carried out using JMP software (SAS Institute, Cary, NC, USA).

\section{Results}

\section{Effects of the timing and concentration of phenidone administration on the adhesion molecule expression of activated HUVECs}

The expression of ICAM-1, VCAM-1, and E-selectin on HUVECs was stimulated by TNF- $\alpha(0.5 \mathrm{ng} / \mathrm{mL})$. We measured the inhibitory effect of phenidone on adhesion 
molecule expression when added either two hours before (pre-incubation), at the same time as (co-incubation), or two hours after (post-incubation) the stimulation of HUVECs by TNF- $\alpha$. The experimental setup is shown in Figure 2. Three different phenidone concentrations were tested: $0.5,1.0$, and
2.0 mM. The results are shown in Figures $3 \mathrm{~A}-\mathrm{C}$. Phenidone significantly decreased the expression of adhesion molecules on the surface of HUVECs when administered two hours before the stimulation of HUVECs by TNF- $\alpha$ ( $\mathrm{p}<0.01$, $(n=4)$. The inhibition of adhesion molecule expression
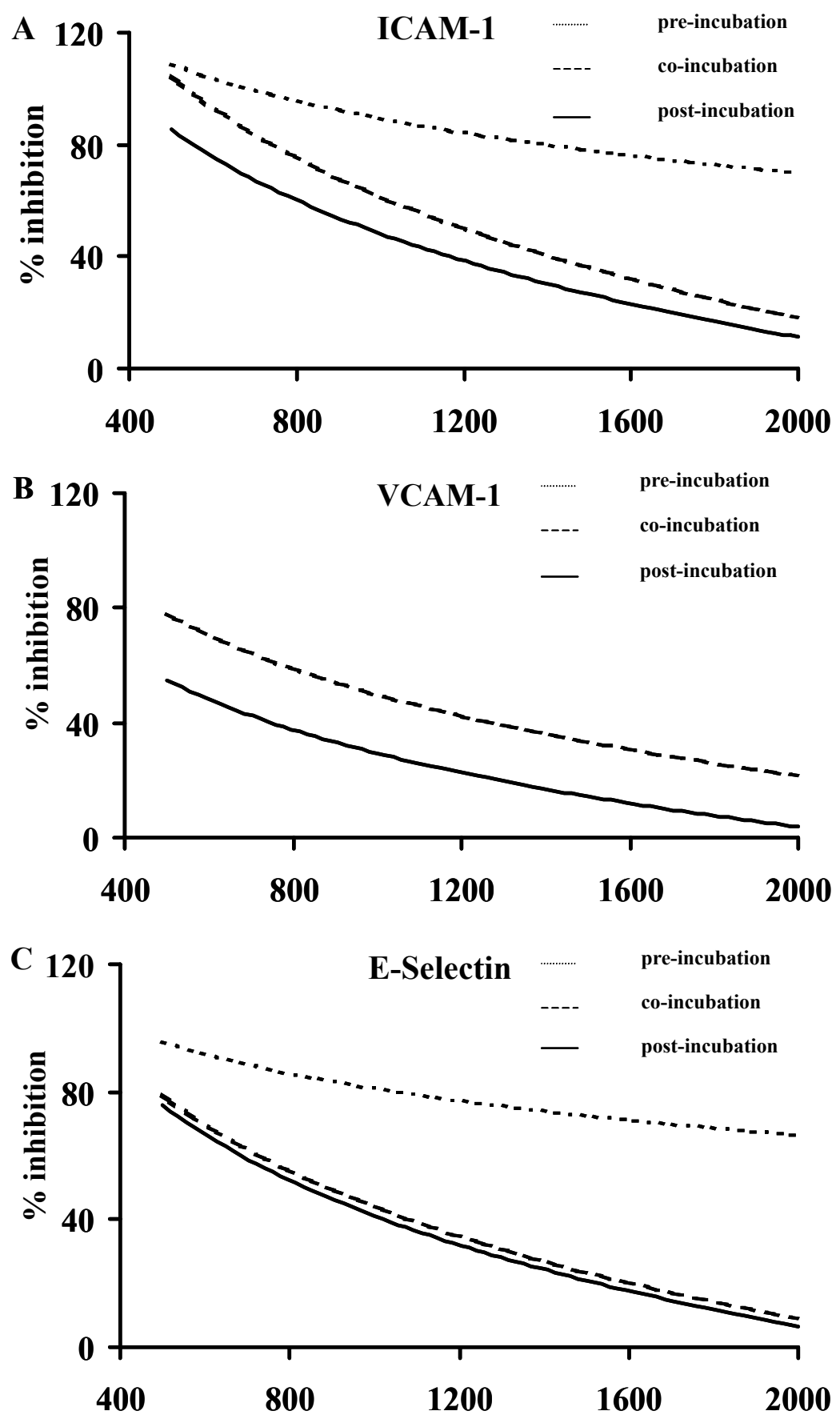

Figure 3 Inhibition of adhesion molecule expression by phenidone.

The decrease of adhesion molecule expression (ICAM-I,VCAM-I, E-selectin) is plotted in a logarithmic dose-response relationship (curve fitting). X-axis: Concentration of phenidone $(\mu \mathrm{M})$. Y-axis: Per cent inhibition of adhesion molecule expression in relation to maximal TNF- $\alpha$ induced expression. Fine-dotted lines: Pre-incubation - phenidone was added 2 hours before TNF- $\alpha$ stimulation. Coarse-dotted line: Co-incubation - simultaneous application of phenidone and TNF- $\alpha$. Solid line: Post-incubation - phenidone was added 2 hours after TNF- $\alpha$ stimulation. 
was still significant when phenidone and TNF- $\alpha$ were co-administered (co-incubation). In contrast, when phenidone was given two hours after the stimulation of HUVEC sy TNF$\alpha$ no decrease in adhesion molecule expression was observed. Furthermore, the inhibition of adhesion molecule expression was concentration-dependent $(\mathrm{p}<0.01)$. The highest phenidone concentration $(2.0 \mathrm{mM})$ led to the greatest inhibition of adhesion molecule expression on HUVECs. There was no statistical difference between the individual inhibitions of the three adhesion molecules tested $(p=0.14)$.

\section{Static effects of phenidone derivatives on the adhesion molecule expression of activated HUVECs}

The ability of the phenidone derivatives 4-methyl-phenidone, 5-methyl-phenidone, 4-4-dimethyl-phenidone, 5-phenylphenidone, and 5-methyl-1,(2,5-di-chloro-phenyl)-3-pyrazolidone to inhibit the adhesion molecule expression on HUVECs was tested when they were administered before the activation of HUVECs (pre-incubation). HUVECs were incubated with increasing concentrations of the derivatives between 125 and $2000 \mu \mathrm{M}$. All experiments were repeated at least three times. To quantify the ability of the derivatives to inhibit adhesion molecule expression, we calculated the inhibitor concentration that lead to a $50 \%$ inhibition of adhesion molecule expression (IC50), assuming a logarithmic dose-response relationship. The results are shown in Figure 4. The expression of ICAM-1 was significantly reduced after pre-incubation of HUVECs with 4-4-dimethyl-phenidone and 5-phenyl-phenidone (IC50 $382 \pm 67 \mu \mathrm{M}$ and $202 \pm 102 \mu \mathrm{M}$, respectively) ( $\mathrm{p}<0.01$ ) compared with the inhibition of adhesion molecule expression by phenidone (IC50 $1128 \pm$ $371 \mu \mathrm{M})$. Similarly, the expression of E-selectin was significantly reduced with these two compounds (IC50 $216 \pm 138$ $\mu \mathrm{M}$ and $169 \pm 41 \mu \mathrm{M}$ ) compared to phenidone (IC50 861 $\pm 338 \mu \mathrm{M})$. In contrast, 4-methyl-phenidone and 5-methylphenidone did not reduce adhesion molecule expression more effectively than phenidone (4-methyl-phenidone: IC50 of $1542 \pm 1062 \mu \mathrm{M}$ for ICAM-1 and $619 \pm 183 \mu \mathrm{M}$ for E.-selectin; 5-methyl-phenidone: IC50 $1615 \pm 819$ for ICAM-1 and $1461 \pm 774 \mu \mathrm{M}$ for E-selectin). No inhibition of the adhesion molecule expression was observed with 5-methyl-1,(2,5-di-chloro-phenyl)-3-pyrazolidone (not shown). Also, compared with phenidone, the expression of

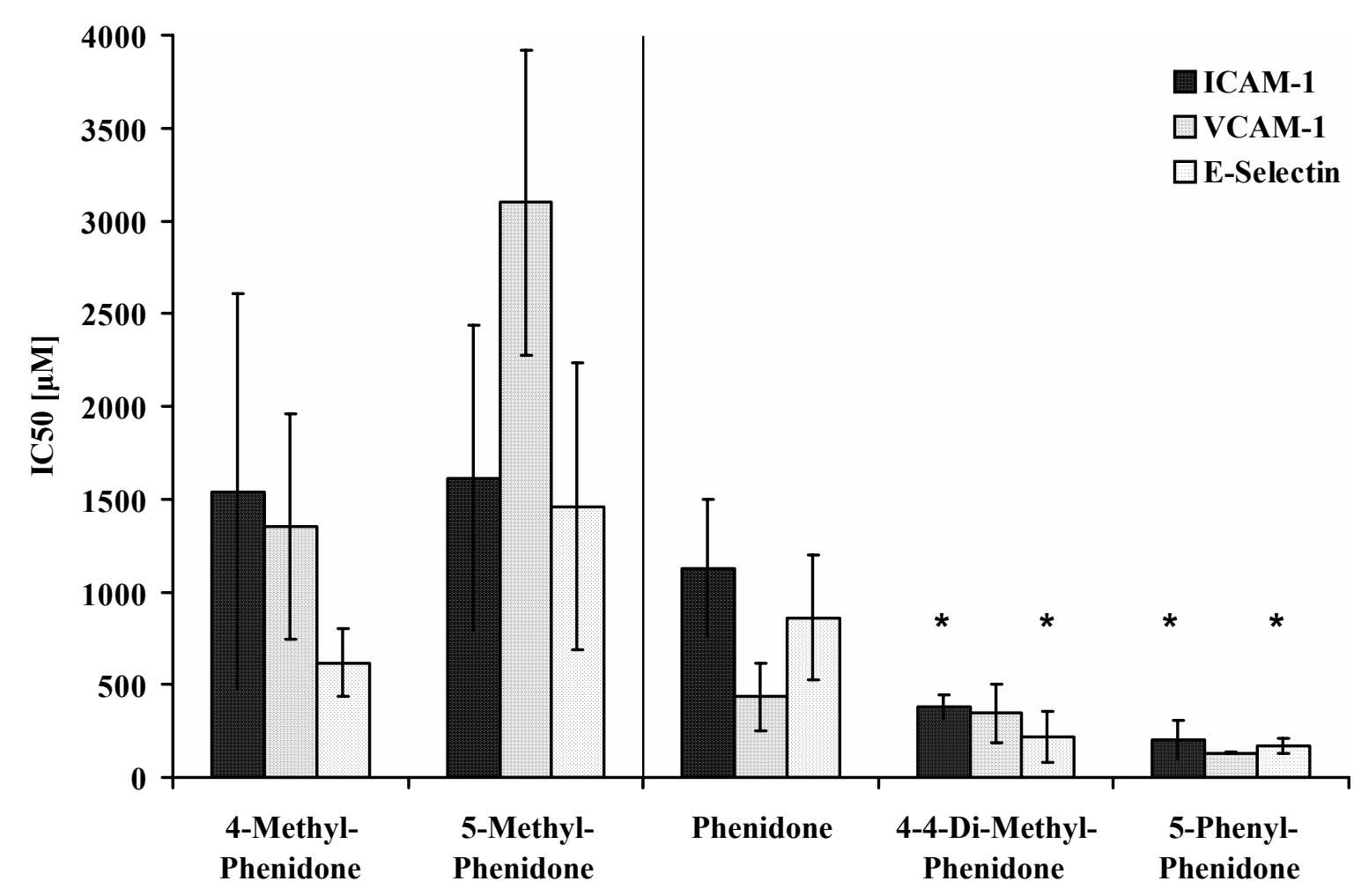

Figure 4 Inhibition of ICAM-I,VCAM-I, and E-selectin by phenidone and derivatives. IC50: The inhibitor concentration yielding $50 \%$ inhibition of adhesion molecule expression. ${ }^{*}=$ significant reduction of ICAM-I, and E-selectin expression after preincubation with the denoted derivative, compared to phenidone $(p<0.01)$. 
VCAM-1 was not significantly reduced after pre-incubation with any of the tested derivatives.

\section{Dynamic adhesion of polymorphonuclear granulocytes to HUVECs}

Under venular shear forces (2 dynes $/ \mathrm{cm}^{2}$ ) PMN adhesion to untreated endothelial cells was negligible after $10 \mathrm{~min}$ of perfusion (not shown). On cytokine-activated HUVECs, total PMN adhesion increased 10-fold (Figures 5A-B). In subsequent experiments, the effect of 4-4-dimethyl-phenidone, which significantly reduced adhesion molecule expression in the static experiments, was compared to phenidone. Pretreatment of endothelial cells with 4-4-dimethyl-phenidone or phenidone (both $400 \mu \mathrm{M}$ ) prior to cytokine-activation significantly reduced total PMN adhesion ( $\mathrm{p}<0.01$; Figures $5 \mathrm{C}-\mathrm{D})$ compared with untreated activated HUVECs. When rolling and firm adhesion were examined separately, it became obvious that 4-4-dimethyl-phenidone had a significantly stronger inhibitory effect on rolling interactions than phenidone $(p<0.05)$. However, the number of adherent PMN was not significantly reduced after preincubation of HUVECs with 4-4-dimethylphenidone rather than phenidone (Figure 6).

\section{Discussion}

The cytokine-triggered expression of adhesion molecules on the surface of vascular endothelial cells is observed in

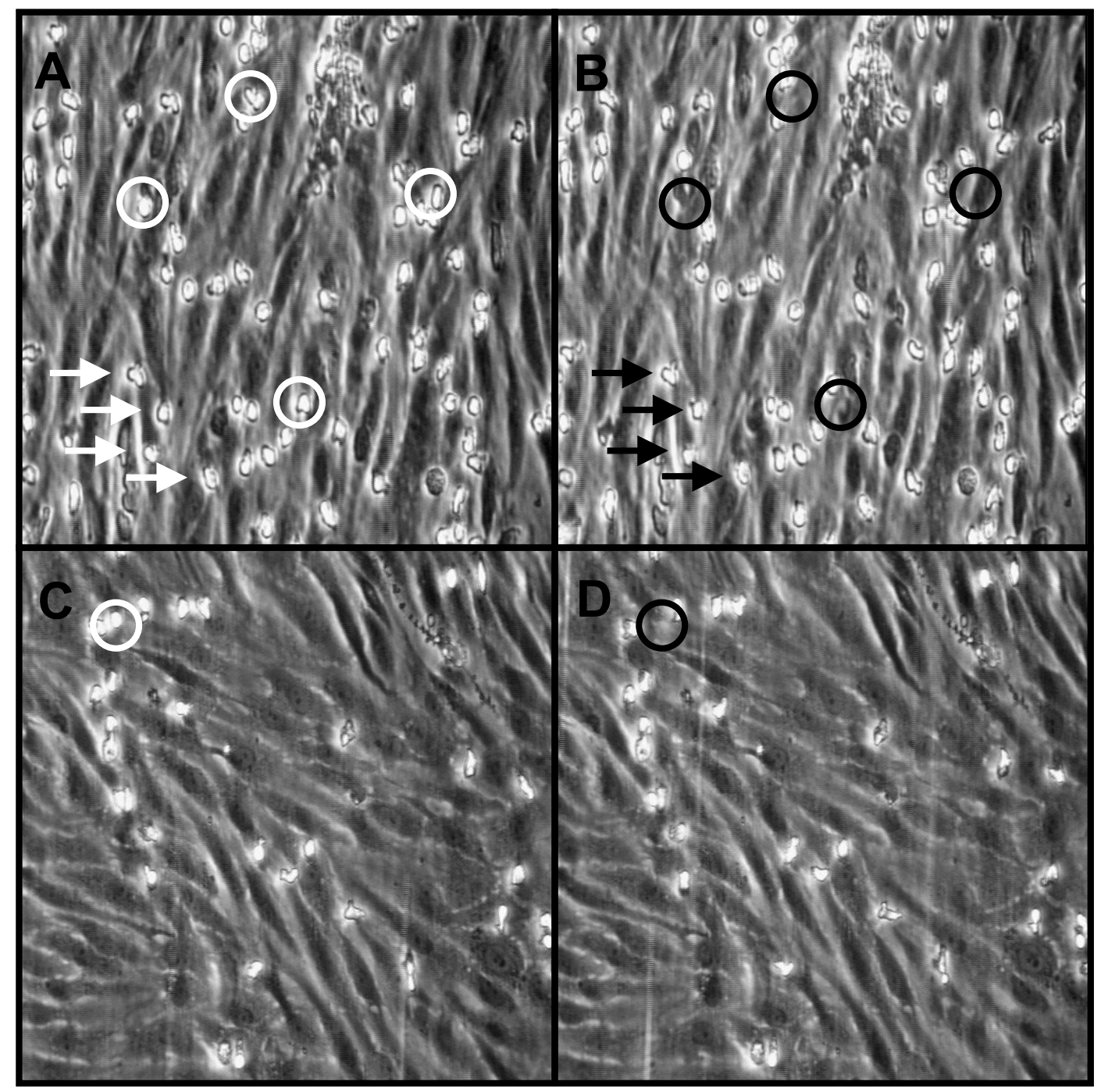

Figure 5 Endothelial-PMN interactions in the flow chamber.

Endothelial cell surface layer after activation with TNF- $\alpha$ for 4 hours. The experiments were performed at a shear stress of 2 dyn $/ \mathrm{cm}^{2}$ with PMN (I $0^{6}$ cells $\left./ \mathrm{mL}\right)$. A: PMN were considered to be adherent (sticking) when a cell moved less than one cell diameter within 10 sec. Four adherent PMNs (flashes) were counted from digitized video recording. B: The same endothelial cell surface as shown in A. PMNs with rolling velocities of $0,7 \mu \mathrm{m} / \mathrm{s}$ were counted as rollers. In A and B four rolling PMNs were marked by circles. C: Endothelial cell surface layer after pre-incubation with 4-4- dimethyl-phenidone (400 $\mu \mathrm{M})$. No adherent PMNs were counted from this sequence. D: The same endothelial cell surface as shown in C. Only I rolling PMN is counted. 


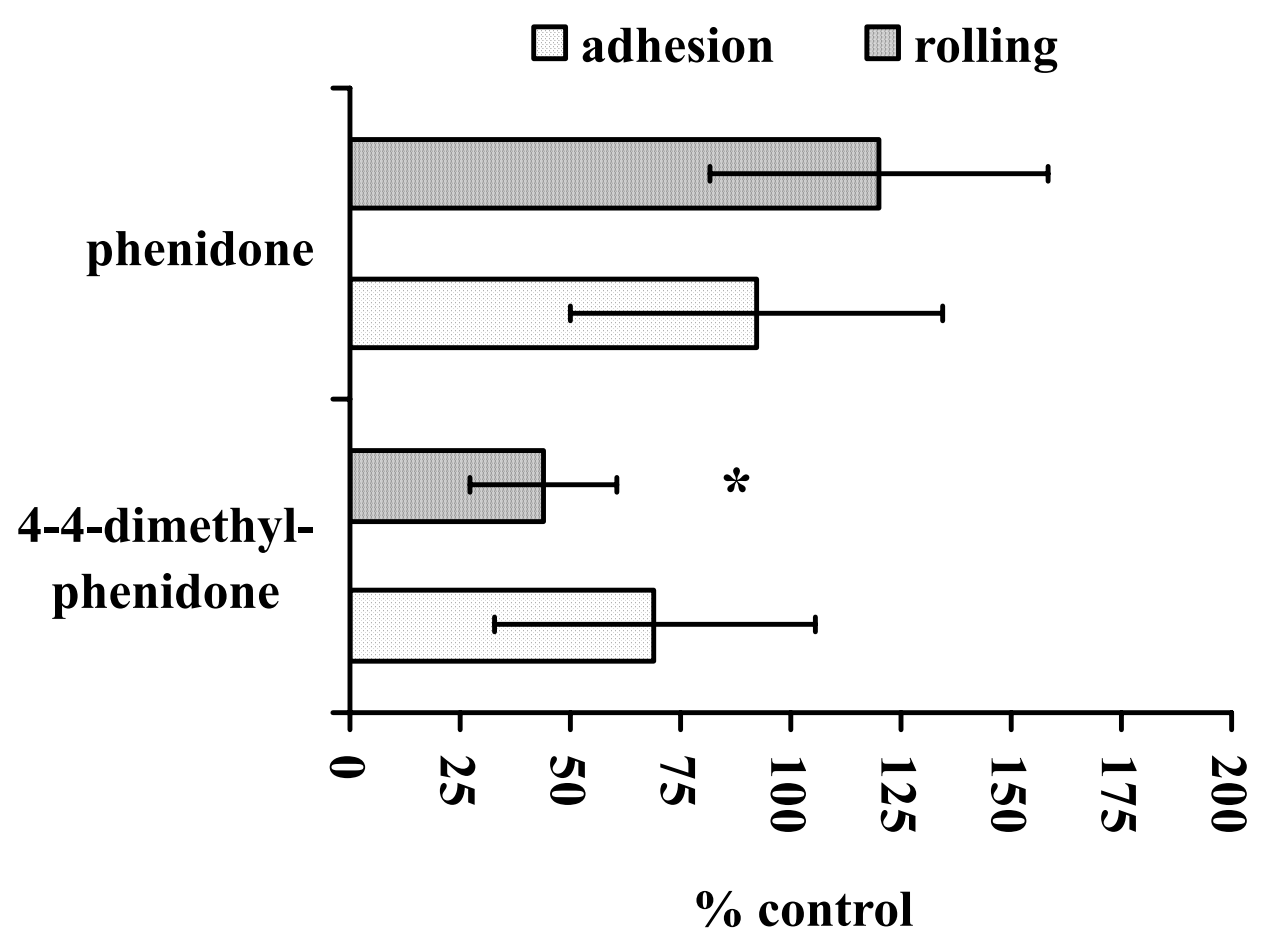

Figure 6 Rolling and adhesion of PMN to TNF- $\alpha$ stimulated HUVECs after pre-incubation with phenidone or 4-4-dimethyl-phenidone.

The ability of phenidone and 4-4-dimethyl-phenidone to inhibit rolling and adhesion of PMNs is shown as per cent of rolling and adhesion to untreated HUVECs. *=significant reduction of rolling when the HUVECs were pre-incubated with 4-4-dimethyl-phenidone instead of phenidone $(p<0.0 \mathrm{I})$.

states of severe sepsis, ischemia reperfusion injury, or SIRS. The inhibition of adhesion molecule expression on activated vascular endothelial cells could be of therapeutic interest for the attenuation of leukocyte-mediated tissue injury (Singbartl and Ley 2000; Peters et al 2003). Using cell-surface antigen analysis and a dynamic adhesion assay, we were able to demonstrate that treatment of cytokine-activated HUVECs with the lipoxygenase inhibitor 1-phenyl-3-pyrazolidinone (phenidone) reduced both adhesion molecule expression and subsequent adhesion of PMN to vascular endothelial cells under postcapillary shear stress. Compared to phenidone, treatment of HUVECs with the derivatives 4-4-dimethylphenidone and 5-phenyl-phenidone was significantly more effective.

The inhibition of adhesion molecule expression was dependent on the time and concentration of the inhibitor. In addition, while treatment before or at the same time as cytokine-triggered activation of adhesion molecule expression led to a reduced adhesion molecule expression, no beneficial effect could be observed when phenidone was administered two hours after TNF- $\alpha$ treatment of HUVECs. Similarly, an effect of phenidone could be demonstrated on leukocyte adhesion in animal models. Leukocyte adhesion was decreased and capillary permeability increased during ischemia-reperfusion injury after pretreatment with phenidone in a hamster cheek pouch model and an ischemic rat brain damage model (Bertuglia et al 1993; Wakatsuki et al 1999). The results of these studies indicate that phenidone affects adhesion molecule expression in vivo. However, it is not clear from these functional studies whether phenidone affects adhesion primarily by inhibition of endothelial adhesion molecules or more proximal steps in the inflammation cascade. We observed a significant inhibitory effect of phenidone on the expression of the endothelial-cell-specific adhesion molecules ICAM-1, VCAM-1, and E-selectin only when it was administered two hours before or simultaneously with TNF- $\alpha$.

In subsequent experiments, we tested five derivatives to determine whether they might have a stronger inhibitory effect on adhesion molecule expression than phenidone. In a previously published study, a series of 1-phenyl-3pyrazolidinones were tested with respect to their ability to inhibit lipoxygenase. In this study, the lipoxygenase inhibitory potency was correlated with the lipophilicity of the compounds. Furthermore, the introduction of a substituent at position four of the pyrazolidinone improved the potency. In our study, we used those derivatives found in a previous study (Hlasta et al 1991) to inhibit 5-lipoxygenase most effectively, and tested them for their ability to inhibit adhesion molecule expression on activated HUVECs. The derivatives 
4-4-dimethyl-phenidone and 5-phenyl-phenidone decreased the adhesion molecule expression of ICAM-1 and E-selectin significantly better than phenidone. We observed that the inhibitory potential of the derivatives on adhesion molecule expression increased as more and more lipohilic side groups were introduced in the molecule.

Pyrazolidinones are combined lipoxygenase and cyclooxygenase inhibitors (Hlasta et al 1991). Several mechanisms of action are conceivable behind adhesion molecule inhibition by pyrazolidinones. These include lipoxygenase inhibition, cyclooxygenase inhibition, antioxydative effects, or a combination of the above. A group tested the effect of nordihydroguaiaretic acid (NDGA), a potent lipoxygenase inhibitor, on the cytokine-triggered inhibition of ICAM-1 and VCAM-1 on HUVECs (Lee et al 1997). The authors of that study showed that both adhesion molecules were effectively inhibited at low concentrations of NDGA (IC50: $50 \mu \mathrm{M}$ ). Their results, like ours, demonstrated that an inhibitory effect only occurred when the inhibitor was added before the cytokine-triggered activation of adhesion molecule expression. Subsequent analysis showed that NDGA inhibited the promotor activity of the gene coding for VCAM-1 by decreasing the functional activity of NF- $\kappa$ B. Several studies demonstrated in similar series of experiments that adhesion molecule expression is inhibited by lipoxygenase inhibitors interacting with the nuclear transcription factor AP-1 (Ahmad et al 1994). The activation of transcription factors NF- $\kappa$ B and AP- 1 by TNF- $\alpha$ triggers the transcription and expression of E-selectin, VCAM-1, and ICAM-1 in HUVECs. The promotors of the corresponding genes possess three, two, and one binding site(s) for NF- $\mathrm{KB}$, respectively (Schindler and Baichwal 1994; Ladebur and Parks 1995; Sheppard et al 1995). It has been shown that lipoxygenase is involved in the signal transduction pathway through the RhoA/protein kinase Ca-dependent activation of NF- $\kappa$ B (Los et al 1995; Bolick et al 2005). Therefore, compounds with improved lipoxygenase inhibition activity could influence the adhesion molecule expression on HUVECs by affecting the activity of NF- $\kappa \mathrm{B}$ and AP-1. However, we did not measure a possible correlation between the lipoxygenase activity of the derivatives and the inhibitory effect on the adhesion molecule expression. For most liopxygenase inhibitors, the reported IC50 for lipoxygenase inhibition is less than that for adhesion molecule inhibition by a factor of about ten (Hlasta et al 1991).

In previous studies, it was shown that the cyclooxygenase inhibitors diclofenac, ibuprofen, and salicylates were able to decrease the expression of adhesion molecules on vascular endothelial cells (Kapiotis et al 1996; Pierce et al 1996; Sakai 1996). However, high concentrations were necessary to achieve an inhibition of ICAM-1 and VCAM-1. The majority of cyclooxygenase inhibitors did not affect Eselectin expression. Further, the cyclooxygenase inhibitor indometacin did not have any effect on adhesion molecule expression on vascular endothelial cells. In contrast to lipoxygenase inhibitors, which lead to an inhibition of adhesion molecule synthesis, cyclooxygenase inhibitors were able to downregulate the number of adhesion molecules already expressed on the surface of endothelial cells. We did not observe a postranslational effect in our experiments with combined lipoxygenase and cyclooxygenase inhibitors. Thus, cylooxygenase inhibition seems to be of less importance for the improved effectiveness of pyrazolidinones.

After treatment with phenidone, VCAM-1 expression on HUVECs was more effectively reduced than that of ICAM-1 and E-selectin. In addition, 4-4-dimethyl-phenidone and 5-phenyl-phenidone reduced the expression of ICAM-1 and E-selectin significantly better than phenidone. Both ICAM-1 and E-selectin participate in the transition from rolling to firm adhesion (De Caterina and Zampolli 2004; Wang et al 2004). Whereas E-selectin decelerates transiently rolling leukocytes, ICAM-1 and VCAM-1 contribute to firm adhesion by binding to $\beta_{2}$-integrins on the neutrophil at slow rolling velocities (Steeber et al 1998; Ley 2003). When we compared phenidone to 4-4-dimethyl-phenidone with respect to their ability to inhibit neutrophil rolling and firm adhesion (sticking) in dynamic flow chamber experiments, we found that rolling was significantly better inhibited after incubation with 4-4-dimethyl-phenidone than with phenidone. This result correlated with the significantly better inhibition of E-selectin by 4-4-dimethyl-phenidone than by phenidone.

We observed a higher rate of cell detachment when we incubated the HUVECs with inhibitor concentrations of $2000 \mu \mathrm{M}$. However, cell morphology was not altered after this treatment. In addition, adhesion molecule expression was preserved even at high concentrations of the inhibitors in our postincubation experiments. The preservation of functional activity as well as the unaltered cell morphology suggests that cell toxicity did not occur at these concentrations.

In summary, we found a correlation between reduced adhesion molecule expression on activated HUVECs and subsequently impaired adhesion of neutrophils following treatment with the phenidone derivatives 4-4-dimethyl-phenidone and 5-phenyl-phenidone. These lipoxygenase inhibitors might be of therapeutical interest in the treatment of overwhelming systemic inflammation during shock, trauma, and sepsis. 


\section{References}

Ahmad M, Theofanidis P, Medford RM. 1994. Role of activating protein-1 in the regulation of the vascular cell adhesion molecule-1 gene expression by tumor necrosis factor-alpha. J Biol Chem, 273:4616-21.

Bertuglia S, Colantuoni A, Intaglietta M. 1993. Effect of leukocyte adhesion and microvascular permeability on capillary perfusion during ischemia-reperfusion injury in hamster cheek pouch. Int J Microcirc Clin Exp, 13:13-26.

Bolick DT, Orr AW, Whetzel A, et al. 2005. 12/15-Lipoxygenase regulates intercellular adhesion molecule-1 expression and monocyte adhesion to endothelium through activation of RhoA and nuclear factor-kB. Arterioscler Thromb Vasc Biol, 25:2301-7.

Bone RC, Balk RA, Cerra FB, et al. 1992. Definitions for sepsis and organ failure and guidelines for the use of innovative therapies in sepsis. The ACCP/SCCM Consensus Conference Committee. American College of Chest Physicians/Society of Critical Care Medicine. Chest, 101:1644-55.

Cuzzocrea S, Rossi A, Serraino I, et al. 2004. Role of 5-lipoxygenase in the multiple organ failure induced by zymosan. Intens Care Med, 30:1935-43.

De Caterina R, Zampolli A. 2004. From asthma to atherosclerosis 5-lipoxygenase, leukotrienes, and inflammation. $N$ Engl J Med, 350:4-7.

Eppihimer MJ, Granger DN. 1997. Ischemia/reperfusion-induced leukocyteendothelial interactions in postcapillary venules. Shock, 8:16-25.

Gaddi A, Cicero AF, Pedro EJ. 2004. Clinical perspectives of antiinflammatory therapy in the elderly: the lipoxigenase (LOX)/cycloxigenase (COX) inhibition concept. Arch Gerontol Geriatr, 38:201-12.

Hlasta DJ, Casey FB, Ferguson EW, et al. 1991. 5-Lipoxygenase inhibitors: the synthesis and structure-activity relationships of a series of 1-phenyl3-pyrazolidinones. J Med Chem, 34:1560-70.

Jaeschke H, Smith CW. 1997. Mechanisms of neutrophil-induced parenchymal cell injury. J Leukoc Biol, 61:647-53.

Kapiotis S, Sengoelge G, Sperr WR, et al. 1996. Ibuprofen inhibits pyrogendependent expression of VCAM-1 and ICAM-1 on human endothelial cells. Life Sci, 58:2167-81.

Ledebur HC, Parks TP. 1995. Transcriptional regulation of the intercellular adhesion molecule-1 gene by inflammatory cytokines in human endothelial cells. Essential roles of a variant NF-kappa B site and p65 homodimers. J Biol Chem, 270:933-43.

Lee S, Felts KA, Parry GC, et al. 1997. Inhibition of 5-lipoxygenase blocks IL-1 beta-induced vascular adhesion molecule-1 gene expression in human endothelial cells. J Immunol, 158:3401-7.

Ley K. 2003. The role of selectins in inflammation and disease. Trends Mol Med, 9:263-8.

Los M, Schenk H, Hexel K, et al. 1995. IL-2 gene expression and NF-kappa $\mathrm{B}$ activation through $\mathrm{CD} 28$ requires reactive oxygen production by 5-lipoxygenase. Embo J, 14:3731-40.
Nohe B, Ruoff H, Johannes T, et al. 2002. A fish oil emulsion used for parenteral nutrition attenuates monocyte-endothelial interactions under flow. Shock, 18:217-22.

Nohe B, Kiefer RT, Ploppa A, et al. 2003. The effects of fresh frozen plasma on neutrophil-endothelial interactions. Anesth Analg, 97:216-21.

Peters K, Unger RE, Brunner J, et al. 2003. Molecular basis of endothelial dysfunction in sepsis. Cardiovasc Res, 60:49-57.

Pierce JW, Read MA, Ding H, et al. 1996. Salicylates inhibit I kappa B-alpha phosphorylation, endothelial-leukocyte adhesion molecule expression, and neutrophil transmigration. J Immunol, 156:3961-9.

Reilly KB, Srinivasan S, Hatley ME, et al. 2004. 12/15-Lipoxygenase activity mediates inflammatory monocyte/endothelial interactions and atherosclerosis in vivo. J Biol Chem, 279:9440-50.

Ramos CL, Kunkel EJ, Lawrence MB, et al. 1997. Differential effect of E-selectin antibodies on neutrophil rolling and recruitment to inflammatory sites. Blood, 89:3009-18.

Sakai A. 1996. Diclofenac inhibits endothelial cell adhesion molecule expression induced with lipopolysaccharide. Life Sci, 58:2377-87.

Schindler U, Baichwal VR. 1994. Three NF-kappa B binding sites in the human E-selectin gene required for maximal tumor necrosis factor alpha-induced expression. Mol Cell Biol, 14:5820-31.

Singbartl K, Green SA, Ley K. 2000. Blocking P-selectin protects from ischemia/reperfusion-induced acute renal failure. Faseb $J, 14: 48-54$.

Singbartl K, Ley K. 2000. Protection from ischemia-reperfusion induced severe acute renal failure by blocking E-selectin. Crit Care Med, 28:2507-14.

Sheppard AM, McQuillan JJ, Iademarco MF, et al. 1995. Control of vascular cell adhesion molecule-1 gene promoter activity during neural differentiation. J Biol Chem, 270:3710-9.

Steeber DA, Campbell MA, Basit A, et al. 1998. Optimal selectin-mediated rolling of leukocytes during inflammation in vivo requires intercellular adhesion molecule-1 expression. Proc Natl Acad Sci USA, 95:7562-7.

Vedder NB, Winn RK, Rice CL, et al. 1988. A monoclonal antibody to the adherence-promoting leukocyte glycoprotein, CD18, reduces organ injury and improves survival from hemorrhagic shock and resuscitation in rabbits. $J$ Clin Invest, 81:939-44.

Wakatsuki A, Izumiya C, Okatani Y. 1999. Oxidative damage in fetal rat brain induced by ischemia and subsequent reperfusion. Relation to arachidonic acid peroxidation. Biol Neonate, 76:84-91.

Wang Y, Zhou B, Li J, et al. 2004. Inhibitors of 5-lipoxygenase inhibit expression of intercellular adhesion molecule-1 in human melanoma cells. Acta Pharmacol Sin, 25:672-7.

Zhao L, Moos MP, Grabner R, et al. 2004. The 5-lipoxygenase pathway promotes pathogenesis of hyperlipidemia-dependent aortic aneurysm. Nat Med, 10:966-73. 